\title{
ОРГАНИЗАЦИИ ОБЪЕДИНЕННЫХ НАЦИЙ - 75 ЛЕТ
}

\section{(c) 2020 Ширёва Ирина Викторовна}

кандидат юридических наук, доцент Департамента международного и публичного права Финансовый университет при Правительстве Российской Федерации, Россия, Москва

E-mail: IVShiryova@fa.ru

\section{(C) 2020 Ширёв Денис Андреевич}

кандидат юридических наук, доцент кафедры Судебной власти, правоохранительной и правозащитной деятельности Юридического института РУДН, Россия, Москва адвокат Московского Центрального Филиала Московской областной коллегии адвокатов, Россия, Москва

E-mail:ne205@yandex.ru

В статье рассматриваются отдельные вопросы деятельности ООН с момента ее создания, анализируются проблемные аспекты и вносятся некоторые предложения в контексте реформирования организации.

Ключевые слова: Генеральная Ассамблея, А. Гуттереш, Комиссия международного права, Международный суд, В. Небензя, Совет Безопасности, ООН, Секретариат, Совет по опеке, Устав ООН, ЭКОСОС, юбилей ООН, ЮНСИТРАЛ.

75 лет назад на конференции в СанФранциско был принят Устав Организации Объединенных Наций, который вступил в силу 24 октября 1945 г., что ознаменовало начало работы универсальной международной межправительственной организации. Устав ООН закрепил очень важные положения о целях и принципах работы организации, обозначил организационную архитектуру органов ООН, кроме того, среди прочих статей особую ценность представляют статьи 33, 41, 42 и 51 Устава.

За время своей работы организацией было уделено внимание таким важнейшим вопросам как: права человека, разоружение, урегулирование конфликтов, защита окружающей среды и другим актуальным темам [1]. Число суверенных членов организации увеличилось до 193 государств.

На встрече, посвященной 75-летию ООН Председатель Генеральной Ассамблеи Волкан Бозкир при открытии торжественного мероприятия, отметил, что сегодня особый день для признания невероятной ценности организации. Он поблагодарил весь персонал Организации Объединенных Наций за самоотверженность, дальновидность и настойчивость, а также В.Бозкир вспомнил тех, кто погиб, сказав, что не случайно Организация Объединенных Наций, ее специализированные учреждения, фонды и программы были удостоены Нобелевской премии мира десятки раз - потому что Организация Объединенных Наций вносит свой вклад в улучшение положения нуждающихся людей на местах. Подчеркнув роль организации в оказании помощи государствам-членам в борьбе с пандемией COVID-19, он сказал, что мир ожидает, что Opганизация Объединенных Наций будет противостоять вызовам в трудные времена, и в этой связи ее персонал готов ответить на них [2].

Генеральный секретарь Организации Объединенных Наций Антониу Гутерреш, отметил, что при своем рождении Организация Объединенных Наций была символом глобального единства. «Сегодня это эпицентр [и] наша миссия более важна, чем когда-либо»,- сказал он, подчеркнув, что международное сотрудничество это единственный способ победить пандемию COVID-19, чрезвычайную климатическую ситуацию, растущее неравенство и распространение ненависти. Приветствуя декларацию Ассамблеи о приверженности делу активизации многосторонности, он заявил, что с нетерпением ожидает инклюзивных и глубоких усилий по укреплению глобального управления и тому, как мир реагирует на нынешние и будущие вызовы. Далее он сказал, что его каждый день вдохновляют талант и самоотверженность персонала Организации Объединенных Наций в Центральных учреждениях и на местах. Их дух служения общему благу питал организацию на протяжении 75 лет, и он 
будет направлять ее в период пандемии и после нее. «Мы никогда, никогда не откажемся от нашей работы по осуществлению прочного видения устава»,- подчеркнул А. Гуттереш [3].

Выступая от имени Совета Безопасности его председатель (в октябре 2020 г.) Василий Алексеевич Небензя (Российская Федерация) заявил, что ни одна другая глобальная организация не обладает легитимностью, созывающей силой и нормативным воздействием Организации Объединенных Наций. И нет такого, который давал бы надежду столь многим людям на лучший мир. «Мы должны гордиться всеми теми, кто внес свой вклад в успех $\mathrm{OOH}$, и мы должны помнить тех, кто принес окончательную жертву». Однако в условиях, когда мир сталкивается с мириадами проблем, еще предстоит пройти долгий путь, прежде чем видение, изложенное в Уставе Организации Объединенных Наций, станет реальностью. «У нас есть повод отпраздновать все, чего мы достигли как сообщество наций за последние 75 лет. Мы также должны опираться на наши коллективные достижения и извлекать уроки из наших недостатков, с тем чтобы выполнить обещания основателей Организации Объединенных Наций». Вновь подтверждая приверженность Совета Безопасности Уставу, он подчеркнул, что все государства и международные и региональные организации должны уважать Устав, повышать его легитимность и продвигаться вперед к миру, основанному на мире, справедливости и процветании, о чем 75 лет назад мечтали основатели организации [4].

В своем выступлении вице-президент ЭКОСОС Коллен Виксен Келапиле (Ботсвана), подчеркнул, что пандемия COVID-19 является самой большой проблемой, стоящей перед международным сообществом со времени создания Организации Объединенных Наций, и она демонстрирует, насколько тесно это сообщество связано сейчас. Международное сообщество нуждается в солидарности, руководствуясь повесткой дня в области устойчивого развития на период до 2030 года и целями в области устойчивого развития. ЭКОСОС является уставным органом, который служит центральной платформой для международного сообщества, вступающего в десятилетие действий и осуществления решений. В настоящее время политический форум высокого уровня собирается под эгидой Совета (ЭКОСОС) и служит руководством для международного сообщества по мере того, как мир оправляется от пандемии и работает над тем, чтобы избежать климатического кризиса и достичь Целей устойчивого развития. Подчеркнув, что Совет является более незаменимым, чем когда-либо, К.В.Келапиле отметил, что, поскольку международное сообщество вновь подтверждает свою приверженность Уставу, оно должно согласиться с тем, что Организация Объединенных Наций не должна испытывать недостатка в ресурсах. Он заявил, что повторная приверженность Уставу может вернуть международное сообщество в нужное русло, подчеркнув, что Совет является важнейшей опорой многосторонности [5].

Говоря о работе ООН и проводя оценку ее 75-летней деятельности можно без всякого преувеличения сказать о том, что ООН остается востребованной организацией, ее главные и вспомогательные органы, несмотря на критику в свой адрес, работают для обеспечения эффективного выполнения уставных целей.

Одним из вспомогательных органов является Комиссия международного права, которая была учреждена Генеральной Ассамблеей в 1947 году для выполнения ее мандата в соответствии со статьей 13 (1) (а) Устава Организации Объединенных Наций «инициировать исследования и выносить рекомендации с целью ... содействие прогрессивному развитию международного права и его кодификации». В соответствии с резолюцией 74/186 Генеральной Ассамблеи от 18 декабря 2019 года Комиссия международного права должна была провести свою семьдесят вторую сессию в отделении Организации Объединенных Наций в Женеве с 27 апреля по 5 июня и с 6 июля по 7 августа 2020 года [6]. В программу работы комиссии были включены следующие темы [7]: иммунитет должностных лиц государства от иностранной уголовной юрисдикции; временное применение договоров; охрана окружающей среды в связи с вооруженными конфликтами; охрана окружающей среды; императивные нормы общего международного права (jus cogens); правопреемство государств в отношении ответственности государств; общие принципы права; повышение уровня моря в связи с международным правом.

Необходимо отметить, с момента создания Комиссии ее рабочая документация, доклады, тексты превратились в обширную исследовательскую базу по широкому кругу важнейших вопросов международного публичного права, таких как: ответственность государств, ответ- 
ственность международных организаций, односторонние акты государств, дипломатическая защита, защита атмосферы, правовой режим исторических вод (включая исторические заливы), режим открытого моря и территориального моря, обязательства по выдаче, преступления против человечности, право на убежище, вопросы гражданства и безгражданства, привилегии и иммунитеты международных организаций, основные права и обязанности государств, общие принципы права, нормы jus cogens, влияние вооруженных конфликтов на договоры и др. [8]

Вспомогательным органом Генеральной Ассамблеи также является Комиссия Организации Объединенных Наций по праву международной торговли (ЮНСИТРАЛ), которая была учреждена Генеральной Ассамблеей в 1966 году (резолюция 2205(XXI) от 17 декабря 1966 года). Учреждая комиссию, Генеральная Ассамблея признала, что различия в национальных законах, регулирующих международную торговлю, создают препятствия для движения торговли, и она рассматривала комиссию в качестве механизма, с помощью которого Организация Объединенных Наций могла бы играть более активную роль в сокращении или устранении этих препятствий [9]. Эффективно осуществлять работу ЮНСИТРАЛ помогают ее 6 рабочих групп: микро-, малые и средние предприятия; арбитраж и примирение / урегулирование споров; реформа урегулирования споров между инвесторами и государством; электронная торговля; право о несостоятельности; продажа судов на основании судебного решения [10].

ЮНСИТРАЛ осуществляет свой мандат путем: координации работы организаций, действующих в этой области, и поощрение сотрудничества между ними; содействия более широкому участию в существующих международных конвенциях и более широкому признанию существующих типовых и единообразных законов; подготовки или содействия принятию новых международных конвенций, типовых законов и единообразных законов и содействия кодификации и более широкому признанию условий, положений, обычаев и практики международной торговли в сотрудничестве, где это уместно, с организациями, действующими в этой области; поощрения путей и средств обеспечения единообразного толкования и применения международных конвенций и единообразных законов в области права международной торговли; сбора и распространения информации о национальном законодательстве и современных правовых изменениях, включая прецедентное право, в области права международной торговли; установления и поддержания тесного сотрудничества с Организацией Объединенных Наций; поддержания связи с другими органами и специализированными учреждениями Организации Объединенных Наций, занимающимися вопросами международной торговли; и принятия любых других мер, которые она может счесть полезными для выполнения своих функций [11].

Благодаря работе комиссии были приняты такие важнейшие документы как: типовой закон ЮНСИТРАЛ об электронной торговле (1996 год); типовой закон ЮНСИТРАЛ об электронных подписях (2001 год); типовой закон ЮНСИТРАЛ об электронных переводных записях (2017 год); типовой закон ЮНСИТРАЛ о Международном торговом арбитраже (1985 год) с поправками, принятыми в 2006 году; арбитражный регламент ЮНСИТРАЛ, значение которых сложно переоценить.

15 марта 2006 года Генеральная Ассамблея учредила Совет по правам человека (резолюцией 60/251). До 2006 года существовала Комиссия по правам человека, которая в результате реформы была упразднена, однако многие механизмы и методы работы были заимствованы созданным Советом, например, учреждение специальных процедур [12]. Так, по состоянию на 7 октября 2020 года насчитывалось 55 специальных процедур, а именно 44 тематических и 11 страновых мандата [13]. При поддержке Управления Верховного комиссара Организации Объединенных Наций по правам человека (УВКПЧ) специальные процедуры осуществляют поездки в страны; принимают меры по отдельным случаям и проблемам более широкого структурного характера, направляя сообщения государствам и другим субъектам, в которых они доводят до их сведения предполагаемые нарушения или злоупотребления; проводят тематические исследования и созывают консультации экспертов, содействуют разработке международных стандартов в области прав человека, участвуют в информационно-пропагандистской деятельности, повышают осведомленность общественности и предоставляют консультации по вопросам технического сотрудничества. Специальные процедуры ежегодно отчитываются перед Советом по правам человека; большинство манда- 
тариев также отчитываются перед Генеральной Ассамблеей. Их задачи определены в резолюциях, устанавливающих или продлевающих их мандаты.

Напомним, что в настоящее время в организационной структуре $\mathrm{OOH}$ обозначены 6 уставных органов, среди которых следует обратить внимание на Совет по опеке. Данный орган сейчас фактически бездействует и согласился собираться по мере необходимости по своему решению или решению своего Председателя, или по просьбе большинства своих членов или Генеральной Ассамблеи, или Совета Безопасности [14]. Его работа была приостановлена с 1 ноября 1994 года. Есть мнение, что необходимо принимать волевое решение, либо его упразднять, либо реформировать [15]. Возможно будет достигнуто понимание и консенсус по упразднению Совета по опеке и видится перспектива определения Совета по правам человека $\mathrm{OOH}$ в качестве главного органа ООН. Поскольку права человека, их поощрение и защита занимают ключевое место в работе всей системы Организации.

Кроме того, приоритетными направлениями совершенствования работы ООН были определены 6 областей, на которых необходимо сосредоточить внимание в рамках реформы управления:

- повышение скорости и оперативности предоставления услуг;

- обеспечение большей согласованности в управленческих структурах;

- укрепление культуры управления служебной деятельностью;

- обеспечение эффективного управления ресурсами для осуществления мандатов;

- повышение транспарентности и подотчетности;

- повышение доверия между государствамичленами и Секретариатом [16].

В письме о реформе ООН от 26.12.2018 г., обращаясь к государствам-членам, Генеральный секретарь отметил: «Я пишу вам, чтобы проинформировать о ряде важных изменений, которые произойдут 1 января 2019 года в результате широкомасштабных реформ, одобренных Генеральной Ассамблеей Организации Объединенных Наций в этом году. В широком смысле смена парадигмы управления, перестройка архитектуры мира и безопасности и переориентация системы развития Организации Объединенных
Наций сделают организацию более эффективной, более подотчетной. Более конкретно, наиболее заметным изменением будет создание новых структур в секретариате Организации Объединенных Наций, включая два департамента в архитектуре управления. Я хотел бы проинформировать вас о пунктах приема государств членов в эти два новых департамента.» [17]. Речь шла о Департаменте по вопросам управления, стратегии (ДУСП), политики и соблюдения и Департаменте операционной поддержки(ДОП).

Новый департамент по вопросам управления, стратегии, политики и соблюдения (ДУСПС) должен стать главным координационным центром для государств-членов и других внешних органов по вопросам, связанным с общим управлением секретариатом. Оперативные вопросы, в том числе связанные с участием государствчленов в операциях по поддержанию мира и специальных политических миссиях будут входить в зону ответственности Департамента оперативной поддержки (ДОП) [18].

ДУСПС должен обеспечить стратегическое лидерство во всех областях управления. Благодаря четким и комплексным глобальным рамкам департамент готов сформировать ориентированную на конкретные результаты и учитывающую риски культуру непрерывного обучения и подотчетности. Кроме того, ДУСПС будет предлагать потенциал управления проектами и поддерживать менеджеров с помощью управления, ориентированного на конкретные результаты, внутренней оценки, управления корпоративными рисками и других методологий для непрерывного совершенствования, инноваций и организационных преобразований.

В свою очередь ДОП, являясь оперативным подразделением Секретариата, будет обеспечивать сквозное руководство и поддержку по вопросам управления цепочками поставок, кадровым вопросам и профессиональной подготовке, требованиям в области ИКТ и поддержке силовых структур примерно 90 подразделениям, включающим более 400 мест службы и отделений. ДОП также обладает потенциалом для обеспечения более детального планирования и оперативной поддержки в особых ситуациях [19].

Следует подчеркнуть, что Секретариат ООН является одним из главных органов ООН организован по ведомственному принципу, причем каждый департамент или управление имеет свою отдельную сферу деятельности и ответ- 
ственности. Отделения и департаменты координируют свою деятельность друг с другом в целях обеспечения сплоченности при выполнении повседневной работы организации в отделениях и местах службы по всему миру [20]. Во главе секретариата Организации Объединенных Наций стоит Генеральный секретарь, в настоящее врем А. Гуттереш. Устав ООН определяет Генерального секретаря как «главного административного должностного лица» организации, которое действует в этом качестве и выполняет «такие другие функции, которые возложены» на него Советом Безопасности, Генеральной Ассамблеей, Экономическим и Социальным Советом и другими органами Организации Объединенных Наций. Устав также уполномочивает Генерального секретаря «доводить до сведения Совета Безопасности любой вопрос, который, по его мнению, может угрожать поддержанию международного мира и безопасности». Каждый год Генеральный секретарь выпускает доклад о работе Организации Объединенных Наций, в котором дается оценка ее деятельности и намечаются будущие приоритеты. Генеральный секретарь также является председателем Координационного совета руководителей системы Организации Объединенных Наций (КСР), который дважды в год собирает вместе исполнительных руководителей всех фондов, программ и специализированных учреждений Организации Объединенных Наций в целях дальнейшей координации и сотрудничества по всему спектру основных и управленческих вопросов, стоящих перед системой Организации Объединенных Наций [21]. Одна из наиболее важных задач, выполняемых генеральным секретарем связана с «добрыми услугами» предпринимаемыми публично и в частном порядке, опираясь на его независимость, беспристрастность и добросовестность, для предотвращения возникновения, эскалации или распространения международных споров.

Главным органом отвечающим за поддержание мира и безопасности является Совет Безопасности, состоящий из пяти постоянных и десяти непостоянных членов. В процессе своей работы Совет учредил вспомогательные органы, такие как:

- Контртеррористический комитет; комитет Совет Безопасности, учрежденный в соответствии с резолюциями 1267 (1999) 1989 (2011) и 2253 (2015) и его Группой по аналитической поддержке и контролю санкций в отношении ИГИЛ (ДАИШ), «Аль-Каиды» и «Талибана» и связанных с ними лиц и организаций; Комитет по нераспространению, созданный в соответствии с резолюцией 1540 (2004) Совета Безопасности и его Группой экспертов. Совет также учредил Рабочую группу по жертвам терроризма в соответствии с его резолюцией 1566 (2004) [22];

- Военно-штабной комитет;

- комитеты по санкциям: по Судану, Сомали, Ираку, Конго, Ливану, КНДР, Ливии, ГвинееБисау, ЦАР, Йемену, Южному Судану, Мали и др. [23]

Экономический и Социальный Совет (ЭКОСОС), состоящий из 54 государств, занимает центральное место в системе Организации Объединенных Наций в деле продвижения трех аспектов устойчивого развития - экономического, социального и экологического. ЭКОСОС выступает центральной платформой для стимулирования дискуссий и новаторского мышления, формирования консенсуса в отношении путей продвижения вперед и координации усилий по достижению согласованных на международном уровне целей. Он предлагает уникальный продуктивный диалог (через Политический форум высокого уровня, Форум по сотрудничеству в целях развития, Молодежный форум) между политиками, парламентариями, учеными, фондами, деловыми кругами, молодежью и более чем 3200 зарегистрированными неправительственными организациями. К числу вспомогательных органов ЭКОСОС относятся региональные экономические и социальные комиссии, функциональные комиссии, содействующие межправительственному обсуждению основных глобальных вопросов, а также специализированные учреждения, программы и фонды, действующие по всему миру в целях воплощения обязательств в области развития в реальные изменения в жизни людей. Реформы, проведенные за последнее десятилетие, в частности резолюция 68/1 Генеральной Ассамблеи, укрепили ведущую роль ЭКОСОС в выявлении возникающих проблем, поощрении инноваций и достижении сбалансированной интеграции трех основных компонентов устойчивого развития - экономического, социального и экологического. ЭКОСОС было поручено уделять особое внимание скоординированной последующей деятельности по итогам крупных конференций и саммитов ООН [24].

Главным судебным органом ООН являет- 
ся Международный суд справедливости [25], он находится в Нидерландах. Суд принимает к рассмотрению только межгосударственные жалобы.

В докладе Международного суда Генеральной Ассамблее (за временной период работы с 1.08.2019 по 31.07.2020) был отмечен высокий уровень его активности. 8 ноября 2019 года Суд вынес свое решение по предварительным возражениям, выдвинутым по делу «Применение Международной конвенции о борьбе с финансированием терроризма и Международной конвенции о ликвидации всех форм расовой дискриминации (Украина против Российской Федерации)». 14 июля 2020 года он вынес решения по существу дел «Апелляция относительно юрисдикции Совета ИКАО по статье 84 Конвенции о международной гражданской авиации (Бахрейн, Египет, Объединенные Арабские Эмираты и Саудовская Аравия против Катара)» и «Апелляция относительно юрисдикции Совета ИКАО по разделу 2 статьи II Соглашения 1944 года о транзите по международным воздушным линиям (Бахрейн, Египет и Объединенные Арабские Эмираты против Катара)» [26].

За обозначенный период времени Судом или его Председателем было также вынесено семь процессуальных постановлений:

- постановлением от 15 августа 2019 года Председатель Суда продлил срок для подачи контрмеморандума Соединенных Штатов Америки по делу «Некоторые иранские активы (Исламская Республика Иран против Соединенных Штатов Америки)»;

- постановлением от 26 августа 2019 года Председатель Суда определил срок, в течение которого Исламская Республика Иран может представить письменное изложение своих замечаний и позиций относительно предварительных возражений, выдвинутых Соединенными Штатами по делу «Предполагаемые нарушения Договора 1955 года о дружбе, экономических отношениях и консульских правах (Исламская Республика Иран против Соединенных Штатов Америки)»;

- постановлением от 8 ноября 2019 года Суд определил срок для подачи контрмеморандума Российской Федерации по делу «Применение Международной конвенции о борьбе с финансированием терроризма и Международной конвенции о ликвидации всех форм расовой дискриминации (Украина против Российской Федерации)»;
- постановлением от 15 ноября 2019 года Председатель Суда разрешил Исламской Республике Иран представить ответ, а Соединенным Штатам - реплику на ответ по делу «Некоторые иранские активы (Исламская Республика Иран против Соединенных Штатов Америки)» и определил сроки для подачи этих состязательных бумаг;

- постановлением от 23 января 2020 года Суд определил сроки для подачи меморандума Гамбии и контрмеморандума Мьянмы по делу «Применение Конвенции о предупреждении преступления геноцида и наказании за него (Гамбия против Мьянмы)»;

- постановлением от 22 апреля 2020 года Суд продлил сроки для подачи меморандума Гватемалы и контрмеморандума Белиза по делу «Территориальная, островная и морская претензия Гватемалы (Гватемала/Белиз)»;

- постановлением от 18 мая 2020 года Суд продлил сроки для подачи меморандума Гамбии и контрмеморандума Мьянмы по делу «Применение Конвенции о предупреждении преступления геноцида и наказании за него (Гамбия против Мьянмы)».

За этот же период Суд провел открытые слушания по следующим пяти делам:

- «Апелляция относительно юрисдикции Совета ИКАО по статье 84 Конвенции о международной гражданской авиации (Бахрейн, Египет, Объединенные Арабские Эмираты и Саудовская Аравия против Катара)», слушания по существу дела, 2-6 декабря 2019 года;

- «Апелляция относительно юрисдикции Совета ИКАО по разделу 2 статьи II Соглашения 1944 года о транзите по международным воздушным линиям (Бахрейн, Египет и Объединенные Арабские Эмираты против Катара)», слушания по существу дела, 2-6 декабря 2019 года;

- «Применение Конвенции о предупреждении преступления геноцида и наказании за него (Гамбия против Мьянмы)», слушания по представленной Гамбией просьбе о временных меpax, 10-12 декабря 2019 года;

- «Иммунитеты и уголовно-процессуальные действия (Экваториальная Гвинея против Франции)», слушания по существу дела, 17-21 февраля 2020 года;

- «Арбитражное решение от 3 октября 1899 года (Гайана против Венесуэлы)», слушание по вопросу о юрисдикции Суда, 30 июня 2020 года. В связи с пандемией коронавирусной инфек- 
ции (COVID-19) это слушание было проведено в формате видеоконференции. Одни члены Суда лично присутствовали на слушании в Большом зале правосудия во Дворце мира в Гааге, тогда как другие участвовали удаленно, а представители Гайаны выступали перед Судом по видеоконференц-связи. Правительство Боливарианской Республики Венесуэла проинформировало Суд, что не будет участвовать в устных разбирательствах [26].

Суд является ключевой частью механизма, созданного Уставом Организации Объединенных Наций для мирного урегулирования межгосударственных споров, и всей системы поддержания международного мира и безопасности. В докладе о своей деятельности Суд отметил возобновленное доверие к нему и то уважение, которое государства демонстрируют, передавая ему на рассмотрение свои споры. Суд будет относиться ко всем делам, которые окажутся в его производстве в предстоящем году, с таким же скрупулезным и беспристрастным вниманием, которое он проявлял в 2019/20 судебном году, а также будет и далее выполнять миссию, возложенную на него Уставом, с максимальной добросовестностью, расторопностью и действенностью [28]. Всё, что делает Суд, направлено на поощрение и укрепление верховенства права; вынося свои решения и консультативные заключения, он способствует развитию и уточнению международного права. При этом Суд старается обеспечить, чтобы его распоряжения были хорошо понятны и максимально широко обнародовались во всем мире, используя для этого свои публикации, развивая мультимедийные платформы и свой веб-сайт, а также проявляя активность в социальных сетях. Веб-сайт Суда, дает доступ ко всей судебной практике Суда и его предшественницы - Постоянной Палаты Международного Суда, а также содержит полезную актуальную информацию [29].

Необходимо отметить, что в современных условиях, когда весь мир пострадал от пандемии Covid-19, OOH тоже испытывает определенные трудности в работе, однако Организация Объединенных Наций продолжает обеспечивать международную координацию и оперативную поддержку на глобальном, региональном и страновом уровнях, а также поддерживает расширение масштабов операций по обеспечению готовности стран и реагированию на них в связи с пандемией. В документе ООН под названи- ем «Всесторонний ответ на COVID-19: спасение жизней, защита общества, лучшее восстановление» [30] подготовленном в сентябре 2020 г. отмечалось, что основное внимание организации уделяется спасению жизней, обеспечению доступности жизненно важных услуг, сохранению домашних хозяйств, платежеспособности предприятий, функционированию цепочек поставок, укреплению институтов, предоставлению государственных услуг и обеспечению прав человека на переднем крае. Это достигается за счет немедленной гуманитарной поддержки наиболее пострадавшего населения в наиболее уязвимых 63 странах с помощью спасательной помощи в рамках глобального Плана Гуманитарного Реагирования (GHRP), а также поддержки более чем 120 странам для немедленного социальноэкономического реагирования, ориентированного на рамки системы развития ООН. На глобальном уровне помощь включает в себя активную информационно-пропагандистскую деятельность в поддержку развивающихся стран, включая прекращение долгового бремени, реструктуризацию долга и расширение поддержки через международные финансовые учреждения. Предотвращение и реагирование на возросший уровень насилия в отношении женщин и девочек также является одной из важнейших функций [31]. Трансформационный процесс восстановления, который ведет к лучшему миру после COVID-19 путем устранения лежащих в его основе уязвимостей и выявления возможностей для трансформационных изменений в направлении более справедливых, равных и устойчивых обществ и экономик. Выход из этого кризиса даст возможность решить проблему климатического кризиса, неравенства, изоляции, пробелов в системах социальной защиты и многих других несправедливостей, которые были выявлены и усугублены. Вместо того чтобы возвращаться к неустойчивым системам и подходам, будет необходимо перейти к возобновляемым источникам энергии, устойчивым продовольственным системам, гендерному равенству, более прочным системам социальной защиты, всеобщему охвату услугами здравоохранения и международной системе, которая может обеспечить последовательное, эффективное и универсальное достижение Целей устойчивого развития. Повестка дня в качестве руководства для того, чтобы обеспечить возможность такого реагирования и создать условия, в которых все 
люди - особенно те, кто находится в опасном положении - могут быть достигнуты, генеральный секретарь ООН также решительно выступает за глобальное прекращение огня и дипломатию: призыв Генерального секретаря к глобальному прекращению огня, прозвучавший 23 марта, настоятельно призвал воюющие стороны во всем мире отступить от военные действия облегчают доставку гуманитарной помощи и открывают окна для дипломатии [32]. Организация Объединенных Наций помогает создать базу знаний и оказывает поддержку национальным директивным органам и другим партнерам, мобилизуя свой опыт для изучения различных последствий пандемии и предлагая соответствующую информацию и консультации, в том числе посредством серии политических брифингов по следующим вопросам:

- население, сталкивающееся с особыми проблемами, включая детей, пожилых людей, женщин (в том числе в качестве жертв насилия), инвалиды, беженцы, мигранты и внутренне перемещенные лица;

- региональные проблемы и особенности: Африка, арабские государства, Латинская Америка и Карибский бассейн, а также ЮгоВосточная Азия;

- ключевые тематические области: лидер- ство женщин и гендерное равенство, долг, формирование социально-экономических ответных мер, психическое здоровье, права человека, продовольственная безопасность, мир труда, города, туризм, образование и всеобщее здравоохранение/готовность. Генеральный секретарь $\mathrm{OOH}$ мобилизовал весь мир на решение вышеупомянутых и других важнейших вопросов, таких как сотрудничество в области вакцины, финансирование и облегчение бремени задолженности, а также на освещение основополагающих проблем, таких как неравенство. Учреждения $\mathrm{OOH}$ также поддерживают правительства и партнеров, дают рекомендации по мерам общественного здравоохранения, авиации, образованию, судоходству, туризму, технологиям, снабжению продовольствием и безопасности, сельскому хозяйству и целому ряду других областей политики, затронутых пандемией [33].

Подводя итог, очевидно, что деятельность ООН с момента ее создания и спустя 75 лет остается очень востребованной во всем мире. Стоит согласиться с утверждением Василия Алексеевича Небензя о том, что в условиях, когда мир сталкивается с мириадами проблем, еще предстоит пройти долгий путь, прежде чем видение, изложенное в Уставе Организации Объединенных Наций, станет реальностью.

\section{Библиографический список}

1. Официальный сайт ООН. [Электронный ресурс] - Режим доступа: // https://www.un.org/ru/sections/whatwe-do/(дата обращения 5.11.2020 г.)

2. Документ ООН [Электронный ресурс] - Режим доступа: // https://www.un.org/press/en/2020/ga12279.doc. htm (дата обращения 05.11.2020 г.)

3. Документ ООН [Электронный ресурс] - Режим доступа: // https://www.un.org/press/en/2020/ga12279.doc. htm (дата обращения 05.11.2020 г.)

4. Документ ООН [Электронный ресурс] - Режим доступа: // https://www.un.org/press/en/2020/ga12279.doc. htm(дата обращения 06.11.2020 г.)

5. Документ ООН [Электронный ресурс] - Режим доступа: // https://www.un.org/press/en/2020/ga12279.doc. htm(дата обращения 05.11.2020 г.)

6. Документ ООН [Электронный ресурс] - Режим доступа: // https://legal.un.org/ilc/(дата обращения 08.11.2020 г.)

7. Документ ООН [Электронный ресурс] - Режим доступа: // https://legal.un.org/ilc/(дата обращения 08.11.2020 г.)

8. Документ ООН [Электронный ресурс] - Режим доступа: // https://legal.un.org/ilc/texts/texts.shtml(дата обращения 08.11.2020 г.)

9. Документ ООН [Электронный ресурс] - Режим доступа: // https://uncitral.un.org/en/about(дата обращения 08.11.2020 г.)

10. Документ ООН [Электронный ресурс] - Режим доступа: // https://uncitral.un.org/en/gateway(дата обращения 08.11.2020 г.)

11. Документ ООН [Электронный ресурс] - Режим доступа: // https://www.ohchr.org/EN/HRBodies/HRC/Pages/ AboutCouncil.aspx(дата обращения 08.11.2020 г.) 
12. Ширёва И.В. Механизмы защиты прав человека в рамках ООН и в ее специализированных учреждениях диссертация ... кандидата юридических наук: 12.00.10 / Российский университет дружбы народов (РУДН). Москва, 2013

13. Документ ООН [Электронный ресурс] - Режим доступа: // https://www.ohchr.org/RU/HRBodies/SP/Pages/ Welcomepage.aspx

14. Документ ООН [Электронный ресурс] - Режим доступа: // https:/www.un.org/ru/sections/about-un/ trusteeship-council/ (дата обращения 08.11.2020 г.)

15. Семянникова А.В. Совет по опеке ООН: упразднить или преобразовать.// В сборнике: Глобализация и публичное право. материалы I Международной научно-практической конференции. 2013. С. 361-368.

16. Документ ООН [Электронный ресурс] - Режим доступа: // https://reform.un.org/content/managementreform(дата обращения 08.11.2020 г.)

17. Документ ООН [Электронный ресурс] - Режим доступа: // https://reform.un.org/sites/reform.un.org/files/ sg_reform_letter_management_en_26dec18.pdf(дата обращения 09.11.2020)

18. Документ ООН [Электронный ресурс] - Режим доступа: // https://reform.un.org/sites/reform.un.org/files/ sg_reform_letter_management_en_26dec18.pdf(дата обращения 09.11.2020)

19. Документ ООН [Электронный ресурс] - Режим доступа: // https://reform.un.org/news/advancing-newmanagement-paradigm-management-reform-action9 (дата обращения 09.11.2020)

20. Сайт ООН [Электронный ресурс] - Режим доступа: // Secretariat / United Nations(дата обращения 08.11.2020)

21. Сайт ООН [Электронный ресурс] - Режим доступа: // The role of the Secretary-General | United Nations Secretary-General(дата обращения 08.11.2020)

22. Сайт ООН [Электронный ресурс] - Режим доступа: // Frequently Asked Questions (FAQs) - United Nations Security Council Counter-Terrorism Committee

23. Сайт ООН [Электронный ресурс] - Режим доступа: // Санкции Совета Безопасности | COBET БЕЗОПАСНОСТИ ООН (un.org)

24. Сайт ООН [Электронный ресурс] - Режим доступа: // About Us | UNITED NATIONS ECONOMIC and SOCIAL COUNCIL(дата обращения 09.11.2020)

25. Сайт Международного суда ООН [Электронный ресурс] - Режим доступа: // Международный Суд ООН | Международный Суд ООН (icj-cij.org) (дата обращения 09.11.2020)

26. Сайт Международного суда ООН [Электронный ресурс] - Режим доступа: // 2019-2020-ru.pdf (icj-cij.org) (дата обращения 09.11.2020)

27. Сайт Международного суда ООН [Электронный ресурс] - Режим доступа: //2019-2020-ru.pdf (icj-cij.org) (дата обращения 09.11.2020)

28. Сайт Международного суда ООН [Электронный ресурс] - Режим доступа: //2019-2020-ru.pdf (icj-cij.org) (дата обращения 09.11.2020)

29. Сайт Международного суда ООН [Электронный ресурс] - Режим доступа: //2019-2020-ru.pdf (icj-cij.org) (дата обращения 09.11.2020)

30. Документ ООН [Электронный ресурс] - Режим доступа: // un-comprehensive-response-to-covid-19.pdf(дата обращения 09.11.2020)

31. Документ ООН [Электронный ресурс] - Режим доступа: // https://www.un.org/sites/un2.un.org/files/uncomprehensive-response-to-covid-19.pdf(дата обращения 09.11.2020)

32. Документ ООН [Электронный ресурс] - Режим доступа: // un-comprehensive-response-to-covid-19.pdf(дата обращения 09.11.2020)

33. Документ ООН [Электронный ресурс] - Режим доступа: // https://www.un.org/sites/un2.un.org/files/uncomprehensive-response-to-covid-19.pdf (дата обращения 09.11.2020) 